\title{
KABLOSUZ ALGILAYICI AĞLARDA KAPSAMA ALANININ ÇOK AMAÇLI EVRIMMSEL ALGORİTMALAR İLE ARTIRILMASI
}

\author{
Feyza YILDIRIM OKAY, Suat ÖZDEMIR \\ Gazi Üniversitesi, Mühendislik Fakültesi, Bilgisayar Mühendisliği Bölümü, Maltepe 06570, Ankara, Türkiye \\ feyzaokay@gazi.edu.tr, suatozdemir@gazi.edu.tr
}

(Geliş/Received: 07.01.2013; Kabul/Accepted: 21.04.2015)

ÖZET

Kablosuz Algılayıcı Ağlarda (KAA) algılayıcı düğümlerin sahaya dağıtımı üzerinde durulması gereken önemli konulardan biridir. Uygun bir dağıtım ile yönlendirme, veri füzyonu, iletişim gibi KAA'daki problemlerin karmaşıklı̆ğ azaltılabilmektedir. Mobil KAA'lardaki (MKAA) düğümler hareket yetenekleri sayesinde ağ içerisinde yer değiştirebilmektedir. Dağıtımın optimizasyonu ile yer değiştirmeden dolayı tüketilen enerji minimize edilerek KAA'ların yaşam süreleri uzatılabilmektedir. Bu makalede uygun dağıtım senaryolarının bulunabilmesi için son zamanlarda geliştirilen çok amaçlı evrimsel algoritmalardan ayrıştırmaya dayalı çok amaçlı evrimsel algoritma (MOEA/D) ve hızlı ve elitist çok amaçlı genetik algoritma (NSGA-II) kullanılmaktadır. Bu çok amaçlı evrimsel algoritmalar ile mobil düğümlerin uygun olarak yer değiştirmesi sağlanarak kapsama alanının maksimize edilmesi ve algılayıcıların ilk pozisyonlarından son pozisyonlarına kadar aldıkları yol hesaplanarak yer değiştirme için gerekli olan enerjinin minimize edilmesi amaçlanmaktadır. Benzetim çalışmaları sonuçları domine-edilemeyen çözümlerin algılayıcıların yer değiştirme mesafeleri ile kapsanan alan arasında bir ödünleşime sahip olduğunu açıkça ortaya koymaktadır.

Anahtar Kelimeler: Kapsama kontrolü, enerji koruması, evrimsel algoritma, mobil algılayıcı ağ, çok amaçlı optimizasyon

\section{IMPROVING COVERAGE IN WIRELESS SENSOR NETWORKS USING MULTI- OBJECTIVE EVOLUTIONARY ALGORITHMS}

\begin{abstract}
Node deployment is one of the important issues to be addressed in Wireless Sensor Networks (WSNs). A proper node deployment scheme can reduce the complexity of problems in WSNs such as routing, data fusion, communication, etc. Sensors in Mobile WSNs (MWSNs) have ability to travel in the network with motion capability. This ability can extend the lifetime of WSNs by minimizing energy consumption due to travelling with optimization of deployment. This paper employs two recently proposed multi-objective optimization algorithms, namely multi-objective evolutionary algorithm based on decomposition (MOEA/D) and fast and elitist genetic algorithm (NSGA-II) to find proper deployment scenarios. These multi-objective evolutionary algorithms aim at relocating mobile nodes to provide maximum sensing coverage area while minimizing the energy required for the relocation. The relocation is defined as the total travel distance of the sensors from their initial locations to their final locations. Simulation results clearly show that the non-dominated solutions have tradeoff between the travelled distance and coverage area.
\end{abstract}

Keywords: Coverage control, energy conservation, evolutionary algorithm, mobile sensor network, multiobjective optimization

\section{GIRISŞ (INTRODUCTION)}

Çok çeşitli uygulama alanlarına sahip Kablosuz Algılayıcı Ağlar (KAA) birçok küçük algılayıcı düğümden oluşmaktadır. $\mathrm{Bu}$ algılayıcı düğümler sağlam ve özerk bir şekilde veri toplayabilmek için farklı konumlara yerleştirilerek dağıtık ă̆ yapısı oluşturulur $[1,21]$. 
KAA'lardaki önemli zorluklardan biri enerji tüketimini minimize eden, yüksek kapsama alanı sağlayan, algılayıcı kayıplarına karşı esneklik gösteren ve uygun hesaplama ile iletişim arasında bir ödünleşim oluşturan ağ mimarisine karar verebilmektir. Akıllı algılayıcı dağıtımı ile algılayıcı sistemlerde kolaylık sağlanır. Bununla beraber, gereksiz ağ iletişimine ihtiyaç azalır.

Mobil Kablosuz Algılayıcı Ağlar (MKAA) her biri algılama, hesaplama, iletişim ve "hareket" özelliklerine sahip dağıtık yapıdaki düğümlerin bir araya gelmesiyle oluşmaktadır. Hareket yeteneği MKAA'ları diğer geleneksel statik ağlardan ayırmaktadır. Bu yetenek sayesinde düğümler belirli bir başlangıç düzeninde alana rastgele atıldıktan sonra alanı en iyi kapsayacak şekilde ă içerisinde yer değiştirebilmektedirler [1]. Bu algılayıcılar, gerçek hayatta araçların varlığını izlemek ve onların hareketlerini takip etmek için savaş alanına dağıtılabilir. Ayrıca nükleer, biyolojik ve kimyasal silahlara karşı olası terörist saldırılarının tespit ve keşfinde uzaktan algılama için dağıtılabilir. Çevre gözetleme uygulamalarında da benzer şekilde orman yangınlarının tespiti için bir ormana ya da tsunami veya deprem tespiti için doğal afet bölgesine bırakılabilir. Kapsamanın en iyi şekilde sağlanması ile istenilen bilgilerin eksiksiz, bir bütün olarak elde edilmesi sağlanır.

Geçmiş çalışmaların çoğu rastgele dağıtılan algılayıcıların hareket ederek maksimum kapsama alanı oluşturmasına yönelik olmuştur. Howard ve arkadaşları [1] numaralı çalışmalarında potansiyel alan tabanlı yaklaşımı önermişlerdir. $\mathrm{Bu}$ yaklaşımda düğümlere engeller konularak ve diğer düğümler tarafindan geri püskürtülerek alanın yeniden inşası yapılmaktadır. [2] numaralı çalışmada yazarlar rastgele dağıtılan algılayıcılar için dağıtım stratejisi olan sanal güç algoritmasını (SKA) önermektedir. Bu stratejide, çekici ve uzaklaştırıcı güçler kullanılarak sanal hareket yolu ve hareket oranına karar verilmektedir. Etkili bir algılayıcı düğüm pozisyonu belirlendiğinde tek seferlik hareket gerçekleştirilir. Ayrıca bu çalışmada, küme başları (cluster head) ile olasılıksal hedef konumlandirma algoritması çalıştırılmıştır. Voronoi diyagramlarına dayalı olarak, [3] numaralı çalışmada yazarlar hedef kapsaması için düğümlerin hareketlerini kontrol eden biri iletişime diğeri de harekete yardımcı olan iki dağıtık protokol kümesi önermektedir. Birinci protokolde dügüumler çok daha iteratif bir şekilde hareket ederek son konumlarına gelmektedir. İkinci protokol olan sanal hareket protokolünde ise, hedef konumlandırması hesaplandıktan sonra düğümler sanal olarak hareket etmekte ve bu yeni konumlar ile dügümlerin gerçekten hareket etmeleri durumunda olacakları konumlar arasında hangi komşuları olduğuna göre yer değişimi yapılmaktadır. [4] numaralı çalışmada Pac ve arkadaşları bilinmeyen bir ortamdaki mobil algılayıcı ağların dağıtım problemine dağıtık ve ölçeklenebilir bir çözüm önermektedir. Buna göre algılayıcı ağ sıvı bir beden ve her düğüm sıvı bir element olarak tasarlanmıştır. Sıvı akışı yerel komşuluk etkileşimlerden de esinlenilerek algılayıcı ağın dağıtımına uyarlanmaktadır. [5] numaralı çalışmada fizikteki moleküllerin yayılma şekillerinden yola çıkılarak yoğunluk kontrollü kendi kendine dağıtım metodu tasarlanmaktadır. Düğümlerin dağıtımında etkili bir metot olan bu çalışmada global bir bilginin elde edilemediği farz edilmektedir. Yoğunluk kontrolü ise her bir düğüm tarafindan eş zamanlı olarak algılayıcı düğümlerin dağıtılmasında kullanılmaktadır. [6] numaralı çalışmada maksimum küme kapsama problemi için iki sezgisel yaklaşım modellenmektedir. Tüm hedeflerin gözlemlenebilmesi ve ağın ömrünün maksimize edilebilmesi için algılayıcı düğümlerin hareketleri aktif ve uyku modu arasında değişim sağlayabilecek şekilde programlanmaktadır. Jia ve arkadaşlarının [7] numaralı çalışmasında hızlı ve elitist genetik algoritma (NSGA-II) ile heterojen algılayıcı ağlarda enerji etkinliği ile kapsama alanı arasında bir dengeleme işlemi yapılmaktadır. Maksimum derecede kapsama sağlanırken aktif algılayıcı düğüm sayısı düşük tutularak enerji tüketimi minimize edilmeye çalışılmaktadır. Konstantinidis ve arkadaşlarının yaptıkları ilk çalışmada [8] çok amaçlı dağıtım ve güç ataması problemi (DGAP) tanımlanarak bu probleme ayrıştırmaya dayalı çok amaçlı evrimsel algoritma (MOEA/D) ve NSGA-II ile çözüm üretilmiştir. Çalışmada limitli sayıdaki düğümlerin konumlarına ve güç seviyelerine karar verilmektedir. Böylece alan kapsaması ve ağ ömrünün eş zamanlı optimizasyonu amaçlanmaktadır. Bir diğer çalışmada [9], yazarlar kbağlantılı DPAP'yi tanımlamaktadır. K-bağlantı kısıtı altında probleme MOEA/D ve NSGA-II algoritmalarıyla kıyaslamalı çözümler sunulmaktadır. [10] numaralı çalışmada ise yazarlar bu çalışmalara ek olarak yoğunluk Dağıtımı ve Güç Ataması Problemini (y-DGAP) tanımlamışlardır. MOEA/D algoritmasını hibrit bir şekilde kullanan yazarlar kapsama ve yaşam ömrünü maksimize ederken aynı zamanda bağlantı kısıtını gerçekleştirmeye çalışmışlardır. Ayrıca $[11,12]$ numaralı çalışmalarda yaşam ömrü ve kapsama kısıtları çok amaçlı parçacık sürü optimizasyonu (MOPSO) ve çok amaçlı genetik algoritma (MOGA) ile optimize edilmeye çalışılmaktadır.

$\mathrm{Bu}$ makalede, MKAA'larda Çok Amaçlı Evrimsel Algoritmaya (ÇAEA) dayalı enerji tüketimini minimize ve ağ kapsamasını maksimize eden algılayıcı düğüm dağıtımına karar verilmektedir. Literatürde de üzerinde sıkça çalışılan konulardan biri olan etkin kapsama problemine, literatürdeki diğer çalışmalardan farklı olarak yer değiştirmeden dolayı tüketilen enerjiyi minimize edecek şekilde yenilikçi iki farklı çok amaçlı evrimsel algoritma (MOEA/D ve 
NSGA-II) ile çözüm sağlanmaktadır. Makalenin geri kalan kısmı ise şu şekilde düzenlenmiştir. 2. Bölümde çok amaçlı evrimsel algoritmadan kısaca bahsedilmiş ve ayrıştırmaya dayalı çok amaçlı evrimsel algoritma (MOEA/D) ve hızlı ve elitist çok amaçlı genetik algoritma (NSGA-II) üzerinde durulmuştur. 3. Bölümde MKAA'larda etkin kapsama kontrolü için evrimsel algoritmalar formulüze edilmiştir. 4. Bölümde, benzetim sonuçlarına yer verilmiş ve son olarak 5. Bölümde sonuç kısmı ve bazı geleceğe yönelik araştırılabilir konular üzerinde durulmuştur.

\section{2. ÇOK \\ AMAÇLI \\ ALGORITMALAR EVOLUTIONARY ALGORITHMS)}

EVRIMSSEL (MULTI-OBJECTIVE

Gerçek hayattaki birçok optimizasyon problemi birden çok amaç içermektedir. Çok amaçlı Optimizasyon Problemi (ÇAOP) şu şekilde ifade edilebilir.

$x \in \Omega$ 'e göre

$F(x)=\left(f_{1}(x), \ldots, f_{n}(x)^{T}\right)$ 'i maksimize et

$x$ burada karar değişkeni vektörüdür. $\mathrm{F}: \Omega \rightarrow \mathbb{R}^{\mathrm{n}} n$ tane gerçek değerli amaç fonksiyonunu içermektedir. $\mathbb{R}^{\mathrm{n}}$ amaç uzayı, $\Omega$ ise arama uzayıdır. Genellikle $f_{1}, \ldots, f_{n}$ kendi aralarında çelişmektedir. Optimumu bulma işlemi $f_{1}, \ldots, f_{n}$ arasında iyi bir ödünleşim oluşturma olarak yorumlanabilir. Böylece ÇAOP'u çözmek için çok-amaç yaklaşımı, amaç uzayında birbirleriyle ödünleşim içerisindeki çözümlerin kısmi bir sıralamasını (en iyi çözümün kullanıcıya göre değiştiği çözüm kümesi) oluşturur.

Tek amaçlı optimizasyonda toplam sıralama kullanılırken, ÇAOP'ler tüm amaçların kümelenmiş ağırlı toplamı kullanılarak çözülebilmektedir. Kümelenmiş ağırlı toplamı için popüler olan ölçeklendirme yaklaşımı doğrusal uygunluk kombinasyonu tekniğidir.

Uygunluk $=\max \sum_{i=1}^{n} w_{i} f_{i}(x)$

Buradaki $w_{i} \geq 0$ ve $i=1, \ldots, n$ ÇAOP'deki $i$. amaç fonksiyonunun önemlilik derecesini gösteren ağırlıklı katsayılardır. Genellikle normalizasyon için $\sum_{i=1}^{n} w_{i}=1$ kabul edilir.

Çok amaçlı Optimizasyon (ÇAO) algoritması domineedilemeyen noktaları bulmak için uygulanabilmektedir. (Pareto seviyesi/Pareto front) $[13,14]$. $x$ ve $y$ iki karar değişkeni olsun, $x y^{\prime}$ yi ancak ve ancak $f_{i}(x) \geq f_{i}(y) \quad \forall i \in\{1,2, \ldots, n\}$ ve $f_{j}(x)>$ $f_{j}(y) \exists j \in\{1,2, \ldots, n\}$ olduğunda domine eder ve $x>y$ ile ifade edilir. O halde, $F(x)$ 'in $F\left(x^{*}\right)$ üzerinde baskın yapacak başka bir $x \in \Omega$ bulunmuyorsa $x^{*} \in \Omega$ için domine-edilemeyen çözüm denilir. Şekil 1'de iki amaç fonksiyonundaki baskınlık ilişsisi ayrıntılı bir şekilde gösterilmektedir [14].

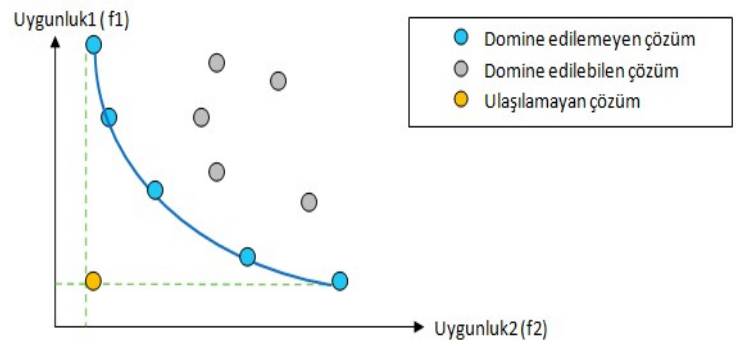

Şekil 1. İkili amaç uzayında baskınlık ilişkisi (Dominance relation in a bi-objective space)

\subsection{Ayrıştırmaya Dayalı Çok amaçlı Evrimsel Algoritma (MOEA/D) (Multi-Objective Evolutionary Algorithm Based on Decomposition (MOEA/D))}

Çok amaçlı evrimsel algoritmalarda problem spesifik bilgilerin birleşimi ile arama uzayında istenilen bölgenin aramaya yönlendirilmesi sağlanır. Ancak ÇAOP için problem spesifik operatörlerin bir bütün olarak tasarımı oldukça zordur. MOEA/D ÇAOP'daki bu zorluğu komşuluk bilgilerini ve sayısal teknikleri kullanarak paralel bir şekilde optimize olan birçok sayısal alt probleme ayrıştırıp hafifletmektedir. Her bir nesilde her bir alt problem için popülasyon o zamana kadarki en iyi çözümleri bir araya getirmektedir (algoritmanın çalışmaya başlamasından itibaren). Alt problemler arasındaki bu komşuluk ilişkisi kümelenmiş katsayı vektörleri arasındaki uzaklığa dayalı olarak tanımlanmaktadır. İki komşu alt problemin optimal çözümleri oldukça benzer olmalıdır. Her bir alt problem (sayısal kümelenmiş fonksiyon) sadece kendi komşu alt problemlerindeki bilgiyi kullanarak MOEA/D içerisinde optimize edilmektedir [16].

MOEA/D'nin genel yapısı şu şekilde sunulabilir [16]: $\lambda^{1}, \ldots, \lambda^{N}$ çift yayılım ağırlık vektörü olsun ve $z^{*}=\left(z_{1}^{*}, \ldots, z_{n}^{*}\right)$ referans noktası olsun. ÇAOP'lerin PF'lerinin yakınsama problemi Tchebycheff tekniğini kullanan sayisal optimizasyon alt problemlere ayrıştırılabilmektedir. Bu yaklaşımda j. alt problemin tek amaçlı optimizasyonu şu şekildedir [17]:

$$
\text { minimize et } g^{\text {te }}\left(x \mid \lambda^{j}, z^{*}\right)=\max \left\{\lambda_{i}^{j} \mid f_{i}(x)-z_{i}^{*}\right\}
$$$$
1 \leq i \leq n
$$

$\lambda^{j}=\left(\lambda_{1}^{j}, \ldots, \lambda_{n}^{j}\right)^{T} \quad$ burada ağırlık vektörüdür. Örneğin, MOEA/D tek bir çalıştırma ile $N$ tane amaç fonksiyonunu eş zamanlı optimize etmektedir. Her bir $t$ neslinde, Tchebycheff yaklaşımı ile MOEA/D

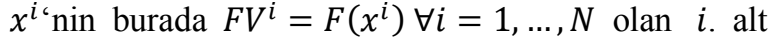
problemin çözümü olduğu $N$ tane noktadan oluşan $x^{1}, \ldots, x^{N} \in \Omega$ bir popülasyonu ve $z_{i}$ 'nin o zamana kadarki amaç $f_{i}$ için bulunan en iyi değer olduğu $z=\left(z_{1}, \ldots, z_{n}\right)^{T}$ bir popülasyonu sağlamaktadır. MOEA/D algoritması $N$ olası çözüm üretir. Oluşturulan $N$ çözüm içerisinden rastgele iki çözüm seçilerek genetik operatörler çalıştırılır. $T$ komşu 
çözüm için $g^{\text {te }}$ değeri hesaplanır. Bu işlem $N$ geçiş içerdiği için MOEA/D algoritmasının hesaplamsal karmaşıklığı $O(M N T)$ 'dir [16]. MOEA/D işlem süreci Şekil 2'deki gibi özetlenebilir [16]:

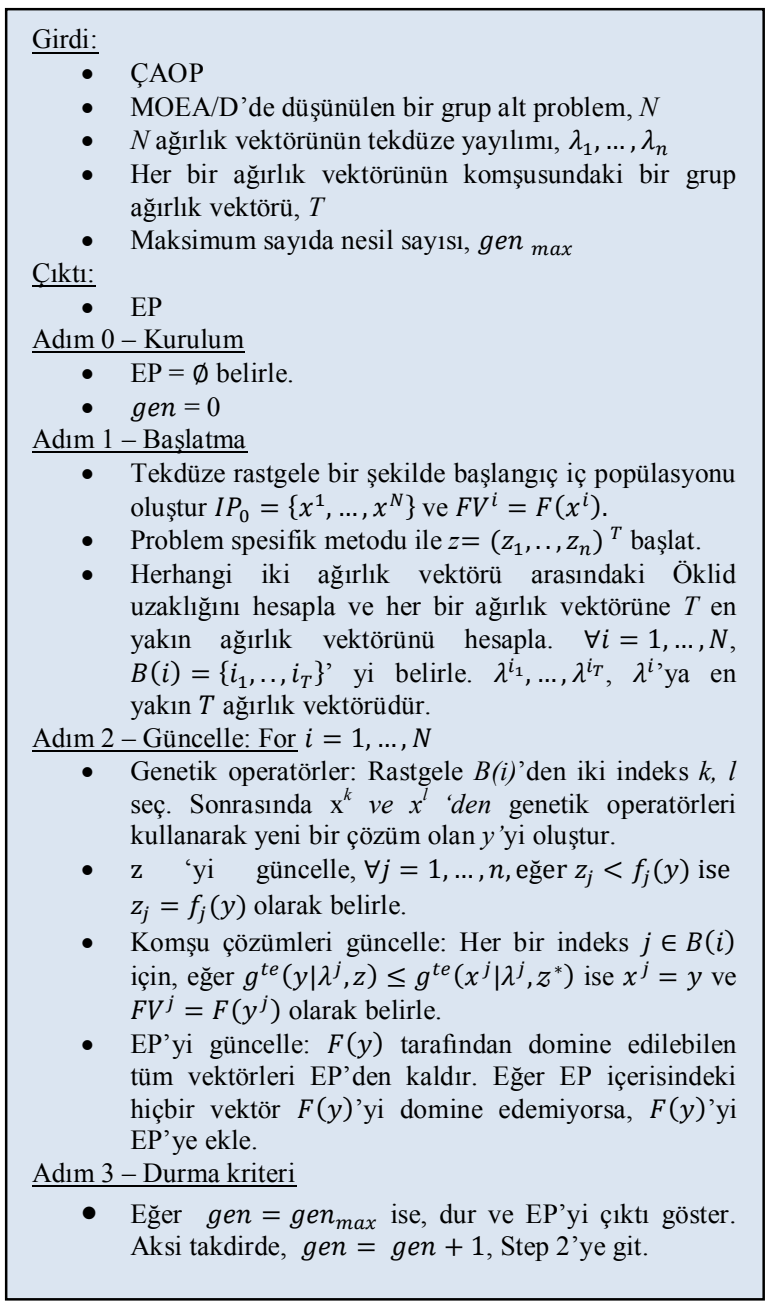

Şekil 2. MOEA/D algoritması (MOEA/D algorithm)

\subsection{Hızlı ve Elitist Çok amaçlı Genetik Algoritma (NSGA-II) (Fast and Elitist Genetic Algorithm (NSGA-II))}

Zaman içerisinde domine-edilemeyen sıralama algoritması (NSGA) [19] üzerinde bazı eleştiriler oluşmuştur. $\mathrm{Bu}$ nedenle NSGA üzerinde bazı iyileştirmeler yapılmıştır. $\mathrm{Bu}$ yeni algoritmaya da seçkin (elitist) domine-edilemeyen siralama algoritması (NSGA-II) [20] adı verilmiştir.

NSGA-II'da yüksek hesaplama karmaşıklığı azaltılmıştır. NSGA-II'ye göre her bir çözümde iki varlık hesaplanır. Birincisi, baskınlık değeri $n_{p}$ ve çözüm $p$ 'yi domine edebilen çözüm sayısıdır. İkincisi ise çözüm $p$ 'nin domine ettiği çözüm kümesi $S_{p}$ 'dir. $\mathrm{Bu}$ da $O\left(M N^{2}\right)$ kadar bir kıyaslama gerektirmektedir. Birinci domine-edilemeyen seviyedeki tüm çözümlerin baskınlık değeri 0'dır. $n_{p}=0$ ile her bir çözüm $p$ için $S_{p}$ kümesinin her bir üyesi $q$ ziyaret edilir ve baskınlık değeri bir azaltılır. $\mathrm{Bu}$ devam ettiğinde, eğer herhangi bir üye $q$ için baskınlık değeri sıfır olursa, farklı bir listeye, $Q$, konulur. $\mathrm{Bu}$ üyeler ikinci domine-edilemeyen seviyeye aittir. Sonrasında, bu prosedür $Q$ 'nun her bir üyesi için tekrar edilir ve üçüncü seviye tanımlanır. Bu süreç ise tüm seviyeler tanımlanana kadar devam eder.

İkinci ya da daha yüksek seviyelerdeki her bir $p$ çözümü için, baskınlık değeri $n_{p}$ en fazla $N-1$ olabilir. Böylece baskınlık değeri sıfir olmadan önce her bir çözüm $p$ en fazla $N-1$ defa ziyaret edilmiş olur. Herhangi bir çözüm domine-edilemeyen seviyeye atandığında asla tekrar ziyaret edilmez. Bu şekilde en fazla $N-1$ adet çözüm olduğu için, toplam karmaşıklık $O\left(N^{2}\right)$ 'dir. Böylece tüm prosedürün karmaşıklığı ise $O\left(M N^{2}\right)$ 'dir. $M$ amaç sayısıdır.

NSGA-II'de paylaşım fonksiyonu yaklaşımı kalabalık-karşılaştırma yaklaşımı ile yer değiştirerek NSGA algoritmasındaki paylaşım fonksiyonundan kaynaklı zorluklar ortadan kaldırılmıştır. Yeni yaklaşım popülasyon üyeleri arasında çeşitliliği sürdürmek için herhangi bir kullanıcı tanımlı parametre gerektirmemektedir. Ayrıca daha iyi bir hesaplamsal karmaşıklığa sahiptir. $\mathrm{Bu}$ yaklaşımda yoğunluk tahmini metriği ve kalabalık karşılaştırması operatörü kullanılmaktadır.

Başlangıçta rastgele bir popülasyon, $P_{0}$, oluşturulur. $\mathrm{Bu}$ popülasyon domine-edilemeyenlere göre siralanır. Her bir çözüme domine-edilemeyen seviyelerine göre bir uygunluk değeri (oran) atanır. Seviye 1 en iyi seviyeyi gösterirken, seviye 2 en iyi ikinci seviyeyi ve seviye 3 üçüncü seviyeyi göstermek üzere devam eder. Uygunlukların minimizasyonu kabul edilir. $N$ büyüklüğündeki yavru popülasyon, $Q$, için ikili turnuva seçimi, rekombinasyon ve mutasyon operatörleri oluşturulur. Popülasyon bir önceki en iyi domine-edilemeyen çözümlerle karşılaştırarak elitizm tanıtılır. Öncelikle popülasyon $R_{t}=P_{t} \cup Q_{t}$ oluşturulur. Popülasyon $R_{t}, 2 N$ büyüklüğündedir. Sonra, popülasyon $R_{t}$ domine-edilememeye göre sıralanır. $R_{t}$ tüm önceki ve şimdiki popülasyon üyelerini içerdiği için elitizm sağlanmış olur. En iyi domine-edilemeyen küme olan $F_{1}$ 'e ait olan çözümler popülasyondaki en iyi çözümlerdir ve popülasyondaki diğer çözümlerden daha fazla üzerinde durulmalıdır. Eğer $F_{1} N$ 'den küçükse, $F_{1}$ kümesinin tüm üyeleri yeni popülasyon için seçilir. Popülasyonda kalan diğer üyeler $P_{t+1}$, domine-edilemeyen seviyelerin alt kümesine seçilir. Böylece, $F_{2}$ kümesindeki çözümler bir sonraki için seçilir ve $F_{3}$ kümesindeki çözümlerle devam eder. $F_{l}$ kümesinin başka bir kümenin uyum sağlayamayacağı sonuncu domine-edilemeyen küme olduğu söylenebilmektedir. Genel anlamda, $F_{1}$ 'den $F_{l}$ 'e tüm kümelerdeki çözümlerin sayısı popülasyon büyüklügünden daha fazla olur. Tam olarak $N$ popülasyon üyesini seçmek için azalan bir sırada kalabalık-karşılaştırma operatörünü $\prec_{n}$ kullanan son 
seviyedeki $F_{l}$ çözümler sıralanır. Sonrasında ise popülasyondaki tüm yerleri doldurmak için en iyi çözümler seçilir. $N$ büyüklüğündeki yeni popülasyon $P_{t+1}$ seçim, çaprazlama ve mutasyon operatörleri kullanılarak $N$ büyüklügündeki yeni popülasyon $Q_{t+1}$ oluşturulur [20]. Domine-edilemeyen çözümler arasındaki çeşitlilik kalabalık karşılaştırma prosedürü ile oluşturulur. Bu prosedür turnuva seçimi içerisinde ve popülasyon azaltma evresinde kullanılır. Çözümler kalabalık uzaklıklarına göre yarıştıklarından (komşuluk içerisindeki çözümlerin yoğunluk miktarı), ayrıca bir niş parametresi gerekli değildir (NSGA'deki $\sigma_{\text {paylașım }}$ gerekmemektedir). Kalabalık uzaklığı amaç fonksiyon uzayında hesaplanmasına rağmen, istenirse ayrıca parametre uzayında da gerçeklenebilmektedir [20].

NSGA-II işlem süreci Şekil 3'teki gibi özetlenebilir:

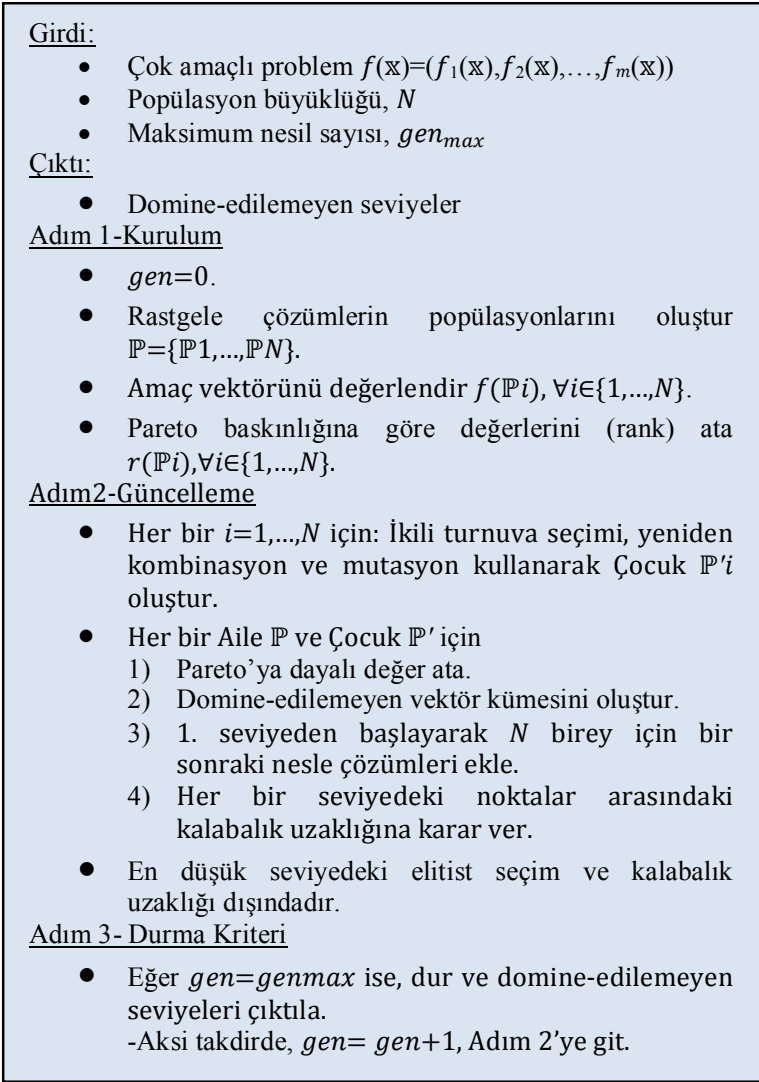

Şekil 3. NSGA-II algoritması (NSGA-II algorithm)

\section{MKAA'LARDA MOEA/D VE NSGA-II ILE KAPSAMA ETKINLIĞİ (MOEA/D AND NSGA-II FOR COVERAGE EFFICIENCY IN MWSNs)}

$\mathrm{Bu}$ bölüm enerji korunumu ve alan kapsama tasarımı konularında MKAA'lar için nasıl bir adresleme yapıldığından bahsetmektedir. Söz konusu problem şu şekilde modellenmiştir: $\mathcal{A}$ boyutları bilinen karesel bir alan olsun. $\mathcal{B} \mathcal{S}$, koordinatları $\left(x_{\mathcal{B} \mathcal{S}}, y_{\mathcal{B} \mathcal{S}}\right) \in \mathcal{A}$ olan baz istasyonu veya çıkış düğümü olsun. $\mathcal{S}_{\Theta_{S}}=$ $\left\{s_{1}, \ldots, s_{k}\right\}$ ise Denklem 4'te de tanımlandığı gibi $k$ adet algılayıcı düğümü başlangıç uzay konumu, kapsama yarıçapları ve başlangıç enerjileriyle birlikte ifade etmektedir (Benzetim ortamında, her bir algılayıcının kapsama alanının 2 boyutlu düzlemde dairesel olduğunu ve dahası tüm algılayıcıların yarıçaplarının eşit $\left(r_{s}\right)$ olduğu kabul edilmiştir. $\mathrm{Bu}$ varsayım algoritmanın benzetimini kolaylaştırmıştır.) Ayrıca, $\mathcal{D}_{\Theta_{\mathcal{D}}}=\left\{d_{1}, \ldots, d_{l}\right\} \quad l$ tane hedef noktasinın kümesi olsun ve $\Theta_{\mathcal{D}}=\left\{\left(x_{d_{1}}, y_{d_{1}}\right), \ldots,\left(x_{d_{l}}, y_{d_{l}}\right)\right\}$ ise bu noktaların uzaydaki konumları olsun.

$\Theta_{\mathcal{S}}=\left\{\left(x_{s_{1}}, y_{s_{1}}, r_{s_{1}}, E_{s_{1}}\right), \ldots,\left(x_{s_{k}}, y_{s_{k}}, r_{s_{k}}, E_{s_{k}}\right)\right\}$

MKAA'lardaki kapsama etkinliği problemi bir parçadaki her bir hedef noktasının $\mathcal{C} \subset \mathcal{D}$ en az bir algılayıcı tarafindan $s \in \mathcal{S}$ kapanmasını sağlamaya yöneliktir. Ancak, minimum gezgin uzaklığ 1 probleminin de düşünülmesi gerekmektedir. Algılayıcıların son konumları ve yer değiştirilen toplam mesafe en iyi kapsamanın enerji etkin bir şekilde olması açısından optimize edilmelidir. Bu çalışmada, bu problem çok amaçlı evrimsel algoritma problemi olarak değerlendirilmiştir. Çalışmanın amacı ise yer değiştirilen mesafe $D$ ‘yi minimize ederken kapsama alanı $\mathcal{C}^{\prime} y i$ artırmaktır. Bu iki amaç arasındaki ödünleşimi gösteren çoklu domineedilemeyen çözümleri elde etmek için MOEA/D ve NSGA-II algoritmaları kullanılmıştır. Aşağıdaki formüller MKAA'lardaki etkin kapsama alanı problemi için sunulan MOEA/D'nin karakteristik bileşenlerini örneklemektedir. MOEA/D'yi 8değişkenli olarak tanımlayacak olursak:

$M O E A / D=(I, \Phi, \Omega, \Psi, \iota, N, E P, \varphi)$

$I$, tam çözüm için kodlanmış birey uzayıdır. Her bir birey Denklem 6'da gösterilen $k$ Kartezyen algılayıcı konumları olarak temsil edilmektedir. Böylece, $I$ bir kromozom ve algilayıcıların konumlarını temsil eden her bir 2D Kartezyen koordinatı da gendir.

$I=\left\{\left(x_{s_{1}}{ }^{\prime}, y_{s_{1}}{ }^{\prime}\right),\left(x_{s_{2}}{ }^{\prime}, y_{s_{2}}{ }^{\prime}\right), \ldots,\left(x_{s_{k}}{ }^{\prime}, y_{s_{k}}{ }^{\prime}\right)\right\}$

Öyleyse, $N$ birey çözümünün bir iç popülasyonu $I P=\left\{I_{1}, \ldots, I_{N}\right\} \in I^{N}, \quad$ şu şekilde belirlenebilmektedir:

$\forall i \in\{1, \ldots, N\}$ ve $\forall j \in\{1, \ldots, k\}$

$I_{i, j}=\left(x_{s_{j}}, y_{s_{j}}\right)$

Algoritmanın ilk adımı başlangıç popülasyonunu oluşturmaktır. $\mathrm{Bu}$ genellikle rastgele yapılmaktadır. İkinci adım popülasyondaki her bir bireyi temsil eden $I P$ için uygunluk vektörünü hesaplamaktır. $\Phi: I \rightarrow \mathbb{R}^{2}$ toplam yer değiştirme uzaklığı $D$ 'yi ve kapsamama cezası $N C$ 'yi bireylere atayan uygunluk fonksiyonu vektörünü belirlemektedir.

$\forall i: 1 \leq i \leq k$

$\Phi_{i}=\left\{D_{i}, N C_{i}\right\}$ 
D böylece Denklem 9'da gösterilen şekilde hesaplanmaktadır.

$D(I)=\frac{\sum_{i=1}^{k}\left|C_{i}-C_{i^{\prime}}\right|}{k}=\frac{\sum_{i=1}^{k} \sqrt{\left(x_{i}-x_{i^{\prime}}\right)^{2}+\left(y_{i}-y_{i^{\prime}}\right)^{2}}}{k}$

$C_{i}$ ve $C_{i}{ }^{\prime}$ burada algılayıcı düğüm $i$ 'nin Kartezyen başlangıç ve bitiş koordinatlarını temsil etmektedir.

$N C$, kapsanmayan hedef noktalarının sayısını minimize etme olarak tanımlanmaktadır:

$N C(I)=\sum_{i=1}^{m}$ Kapsanmayan $\left(d_{i}\right)$

$\operatorname{Kapsanmayan}\left(t_{i}\right)=$

$\left\{0\right.$ if $\exists s \in \mathcal{S}$ and $d\left(s, t_{i}\right) \leq r_{s}$

1 otherwise

$\Omega$, genetik operatörler kümesidir: seçme, çaprazlama, mutasyon. Her biri $\Theta$ tarafindan özetlenen belirli parametlerle kontrol edilmektedir.

$\Omega=\left\{s_{\Theta_{S}}, c_{\Theta_{c}}, m_{\Theta_{m}} \mid s_{\Theta_{S}}, c_{\Theta_{c}}, m_{\Theta_{m}}: I^{N} \rightarrow I^{N}\right\}$

Çaprazlama ve mutasyon popülasyondaki birey çözümlerini değiştirebilen karıştırma operatörleridir. Bizim problemimizde değişkenler, optimize için ihtiyaç duygulan algılayıcıların Kartezyen koordinatlarıdır. Popülasyondaki aile çiftlerinin oranı $p_{c}$, çaprazlama için seçilir. Bir partner seçildiğinde, rastgele sayıdaki gen (algılayıcıların konumu $r 1$ ) rastgele seçilip $\{1, \ldots, k-1\}$ aralığında yer değiştirirler. Böylece Denklem 13'te gösterilen iki çocuk ortaya çıkar. Şekil 4 ise her bir 10 gendeki iki birey çözümü için çaprazlama örneğini göstermektedir. Seçilen $r 1$ ve $r 2$ değerlerine göre bu genler arasında kalan genler çaprazlama ile yer değiştirirler. Sonuçta ise çaprazlamaya uğramış genlerden farklı olan iki gen yapısı oluşur. Amaç çeşitlilik sağlamak ve böylece daha iyi çözümler sağlayan yeni bireyler oluşturmaktır. Örnekte, $r 1=5$ ve $r 2=7$ seçilmiştir.

$c_{p_{c}}: I^{2} \rightarrow I^{2}$

$I_{1}^{\prime}=\left(I_{1,1}, \ldots, I_{1, r 1}, I_{2, r 1+1}, \ldots, I_{2, r 2}, I_{1, r 2+1}, \ldots, I_{1, k}\right)$

$I_{2}^{\prime}=\left(I_{2,1}, \ldots, I_{2, r 1}, I_{1, r 1+1}, \ldots, I_{1, r 2}, I_{2, r 2+1}, \ldots, I_{2, k}\right)$

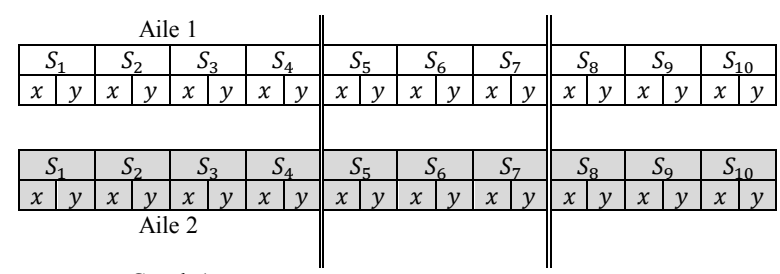

\begin{tabular}{|c|c|c|c|c|c|c|c|c|c|c|c|c|c|c|c|c|c|c|c|}
\hline & & & & & & & & & & & & & & & & & & & \\
\hline$\underline{S}$ & & $\underline{S}$ & 2 & $S$ & 3 & & & $S$ & & $S$ & & $S$ & & $S_{\varepsilon}$ & & $S_{g}$ & & $S_{1}$ & \\
\hline$x$ & $y$ & $x$ & $y$ & $x$ & $y$ & $x$ & $y$ & $x$ & $y$ & $x$ & $y$ & \begin{tabular}{l|}
$x$ \\
\end{tabular} & $y$ & $x$ & $y$ & $x$ & $y$ & \begin{tabular}{|l|}
$x$ \\
\end{tabular} & \\
\hline
\end{tabular}

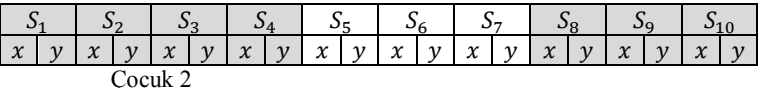

Şekil 4. 2-noktalı çaprazlama örneği (An example of 2point crossover)
Yeni bireylerdeki her bir gen çifti böylece olasılık $p_{m}$ 'e göre mutasyona uğratılır. Kromozomlardaki her bir gen için yazı gelme olasılığının $p_{m}$ ve tura gelme olasılığının 1- $p_{m}$ olduğu bir para atışı yapılır (biased coin flip). Para atışı yazı geldiğinde, gen ve değiştirilmiş kromozomun yeni popülasyonun üyeleri olması için Denklem 14'teki gibi yeni bir rastgele algılayıcı konumu seçilmektedir. Para atışı tura geldiğinde ise, algılayıcı konumlarında herhangi bir değişiklik yapılmamaktadır. Şekil $5, S_{4}$ geninde meydana gelen bir mutasyon örneğini göstermektedir.

$I_{i, j}^{\prime}=\left(x_{s_{j}}{ }^{\prime}, y_{s_{j}}{ }^{\prime}\right) \mid x_{s_{j}}{ }^{\prime}$ ve $y_{s_{j}}^{\prime} \in \mathcal{A}$

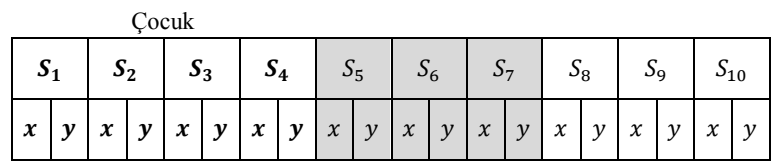

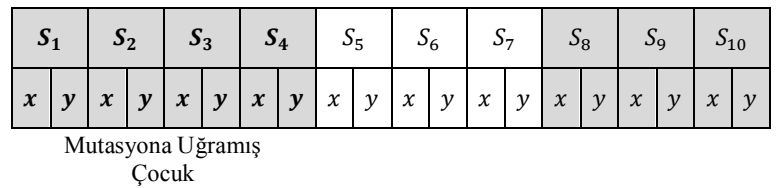

Şekil 5. Mutasyon örneği (An example of mutation)

$\mathrm{Bu}$ aşamada oluşturulan çocuk alt problemin komşuluğunun güncellenmesi için kullanılabilmektedir. Ayrıca, bu çocuk EP'nin durumunu da güncelleyebilmektedir. Güncelleme fonksiyonu $\quad \Psi: \mathrm{EP} \rightarrow E P^{\prime}, \quad E P^{\prime}$ yi, $I^{N^{\prime}}$ ne $\Omega$ uygulanırken domine-edilebilen ve/veya edilemeyen çözümleri kaldırarak ve/veya ekleyerek güncelleme süreci olarak tanımlanabilir. Son olarak, $\iota: I^{N} \rightarrow$ \{true,false\} MOEA/D için bir sonlandırma kriteridir. Karar verme fonksiyonu $\varphi: \mathrm{EP} \rightarrow I^{*} E P$ dışından bir birey $I^{*}$ seçebilmekte (minimum kabul edilebilir kapsamaya eşit veya fazla bir kapsama alanı oluşturan ve minimum yer değiştirme uzaklığı sağlayan bir çözüm seçmek için) ve bunu belirgin bir MKAA tasarımına çözümleyebilmektedir.

MKAA'larda NSGA-II ile etkin kapsama kontrolü sağlanırken öncelikle başlangıç popülasyonu $P_{0}$, rastgele bir şekilde oluşturulur. Popülasyondaki bireyler Denklem 15'teki hesaplama ile birbirleriyle karşılaştırılmaktadır. $i$ kendine eşit olmayan $j$ bireyleriyle karşılaştırılarak domine ya da domineedilemeyen olarak etiketlenir. Bireylerin uygunluk değerleri Pareto-optimal'e göre kiyaslanarak etiketlemeler yapılır.

$d_{i j}=\sqrt{\sum_{p=1}^{p}\left(\frac{x_{p}^{(i)}-x_{p}^{(j)}}{x_{p}^{(u)}-x_{p}^{(l)}}\right)}$

$p$ burada problemdeki değişken sayısıdır. Parametre $x_{p}^{u}$ ve $x_{p}^{l}, x^{p}$ değişkeninin alt ve üst sınırlarıdır. Her bir birey etiketlendikten sonra sanal uygunluk değeri 
ile tüm bireyler seviye değeri alır. Diğer bireyler için kontrol edilmesi gereken şey daha alt seviyedeki bireylerin sanal uygunluk değerlerinin üst seviyedeki minimum sanal değerinden daha küçük olması gerektiğidir. Ayrıca minimum uygunluk değerinin delta-sanal olarak belirlenen bir alt sinırdan daha az olması durumunda minimum sanal değeri arttırılır.

Tüm bireylerin seviyeleri belirlendikten sonra popülasyondaki bireyler turnuva seçimine göre belirlenir ve daha sonra çaprazlama ve mutasyon operatörleri ile çeşitlilik sağlanır. $\mathrm{Bu}$ operatörler MOEA/D'de kullanılan seçme, çaprazlama ve mutasyon operatörleridir.

\section{BENZETIM ORTAMI SONUÇLARI (SIMULATION RESULTS)}

Benzetim çalışmalarına göre her bir MKAA $100 m \times$ $100 \mathrm{~m}$ 'lik bir alana rastgele bir şekilde dağıtılmış 25 adet algilayıcı düğümden ve 50 adet hedef noktasından oluşmaktadır. Bu ise her bir algılayıcı ve hedefin yatay ve dikey koordinatlarının 0 ile boyutların maksimum değeri olan 100 arasında rastgele seçildiği anlamına gelmektedir. Koordinatları verilen algılayıcı ve hedefler ağ içerisinde konumlanmış olmaktadırlar.

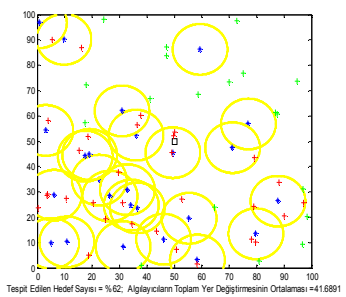

(a)

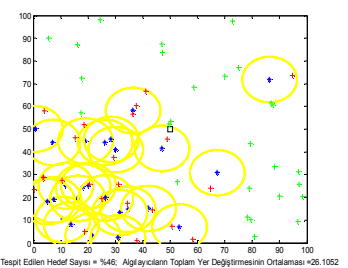

(e)

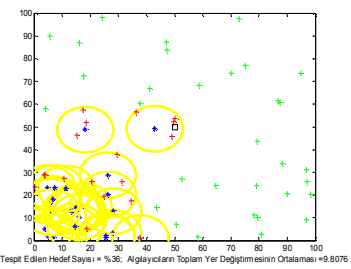

(i)

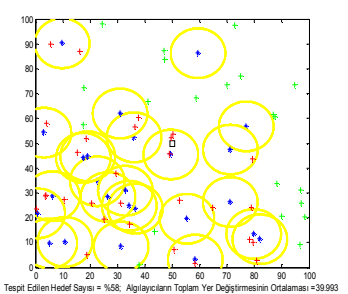

(b)

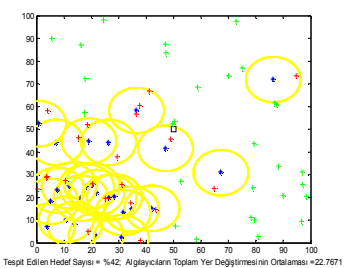

(f)

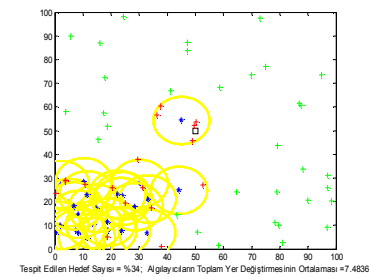

(j)

Ancak algılayıcıların MOEA/D ve NSGA-II algoritmaları ile bulundukları konumlardan ağ alanı içerisinde yer değiştirmelerini görebilmek için başlangıç kartezyen koordinatları ağ alanı $\mathcal{A}$ 'nın $25 m \times 25 m$ 'lik alana sahip bir köşesinde seçilmiştir. Baz İstasyonu (BS) merkezi olarak kabul edilmiştir (herhangi bir düğümün BS'ye maksimum uzaklığı yaklaşık $70 \mathrm{~m}^{\prime}$ dir). Evrimsel bileşenler olarak ikili turnuva seçimi, $p_{c}=0,6$ oranla 2-noktalı çaprazlama, $p_{m}=0,03$ oranla mutasyon olarak belirlenmiştir. Popülasyon büyüklüğü $N=100$ olarak alınıp 600 nesil için evrimleşmesine izin verilmiştir. Komşuluk büyüklüğü $T=5$ olarak seçilmiştir.

Problemin çözümü için öncelikle uygunluk fonksiyonları belirlenmiştir. Enerji etkin kapsama probleminde iki amaç bulunmaktadır. Amaçların ilkinde kapsama maksimize edilmeye çalış1lırken diğerinde ise enerji tüketimi minimize edilmeye çalışılmaktadır.

Kapsamanın maksimimizasyonunda toplam kapsanan hedef sayısı kontrol edilirken enerji minimizasyonunda düğümlerin yer değiştirmesi minimize edilmektedir. Her iki kriterin maksimizasyon ya da minimizasyon yapması gerekli

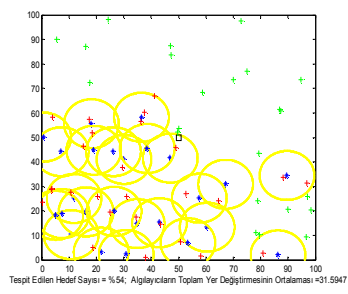

(c)

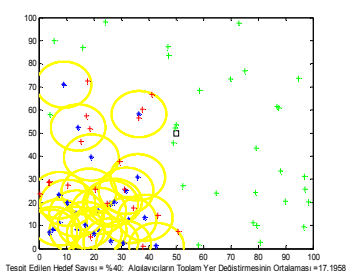

(g)

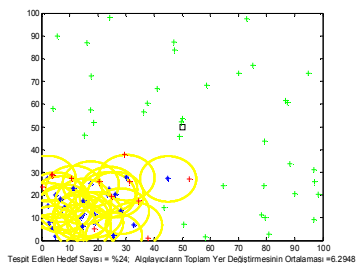

(k)

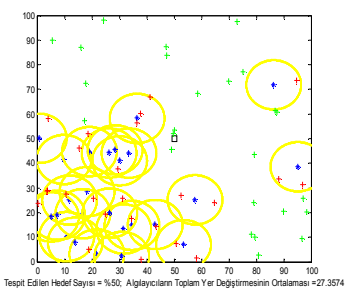

(d)

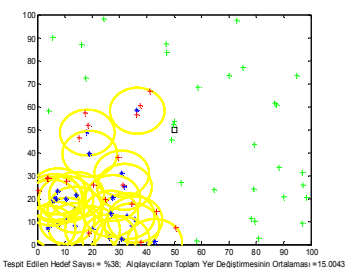

(h)

Şekil 6. MOEA/D ile 600. nesilden sonraki EP çözüm kümesi (a) EP çözüm kümesi \#1, (b) EP çözüm kümesi \#2, (c) EP çözüm kümesi \#3, (d) EP çözüm kümesi \#4, (e) EP çözüm kümesi \#5, (f) EP çözüm kümesi \#6, (g) EP çözüm kümesi \#7, (h) EP çözüm kümesi \#8, (i) EP çözüm kümesi \#9, (j) EP çözüm kümesi \#10, (k) EP çözüm kümesi \#11 (EP solution set with MOEA/D after 600 generations (a) EP solution set \#1, (b) EP solution set \#2, (c) EP solution set \#3, (d) EP solution set \#4, (e) EP solution set \#5, (f) EP solution set \#6, (g) EP solution set \#7, (h) EP solution set \#8, (i) EP solution set \#9, (j) EP solution set \#10, (k) EP solution set \#11) 
olduğu için birinci amaç kapsanmayan hedeflerin minimizasyonu olarak değiştirilmiştir.

Ayrıca toplam yer değiştirme algılayıcı düğüm sayısına bölünerek algılayıcıların toplam yer değiştirmesinin ortalaması alınmıştır. Buna göre uygunluk fonksiyonları şu şekilde tanımlanmıştır;

$f_{1}($ Uygunlukl $)=$ Toplam kapsanmayan hedef sayıs

$f_{2} \quad$ (Uygunluk2) $=$ Toplam yer değiştirmesinin ortalamas1

Şekil 6'da 600 nesilden sonraki evrimleşen EP kümesinden çıkartılan 11 farklı domine-edilemeyen çözümler sunulmaktadır. Her bir çözüm, bu çözümlere karşılık gelen Uygunluk1 ve Uygunluk2 fonksiyonları ile MKAA olarak gösterilmektedir.

Bunun yanı sıra Şekil 7'de EP domine-edilemeyen çözümler çizge olarak sunulmuştur. Bu çizgede Uygunluk1 ile Uygunluk2 arasındaki ödünleşim açıkça görülebilmektedir.

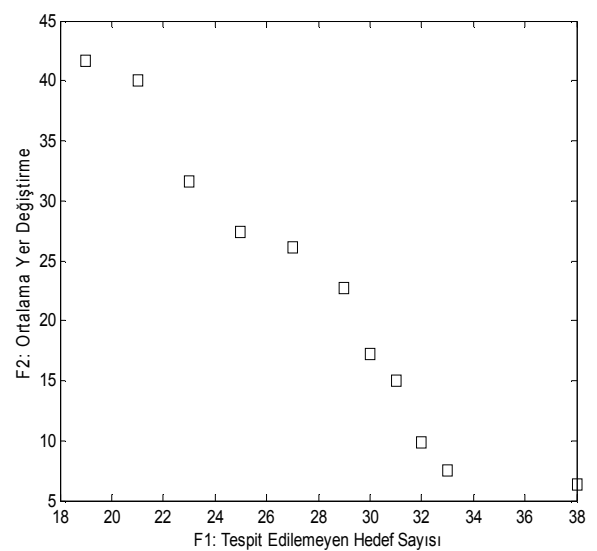

Şekil 7. MOEA/D ile EP domine-edilemeyen çözümlerin çizge olarak gösterimi (EP non-dominated solutions with MOEA/D as a graph)

Aynı başlangıç dağıtımı için bir diğer çok amaçlı optimizasyon algoritması olan NSGA-II çalıştırılmıştır.

Buna göre Şekil 8'de EP çözüm kümesinden çıkartılan çözümler sunulmaktadır. Şekil 9'da bu çözümler çizge olarak gösterilmektedir. Ayrıca, uygunluk değerlerinin MOEA/D ve NSGA-II ile niceliksel olarak karşılaştırmalı sonuçları Tablo 1 'deki gibidir.

Burada EP çözümlerinin farklı gösterim şekilleriyle sunulması her iki kısıt arasındaki ödünleşimi belirgin hale getirmektedir.

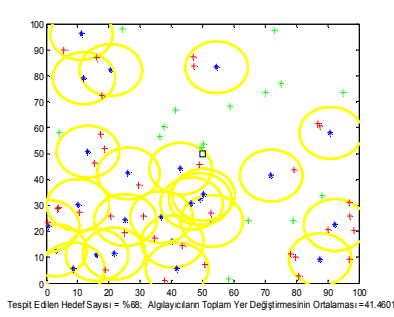

(a)

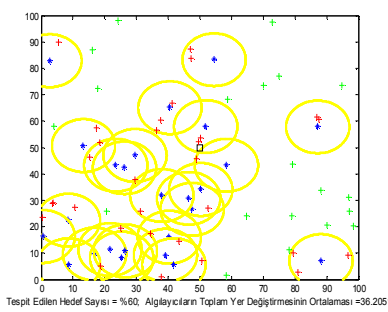

(c)

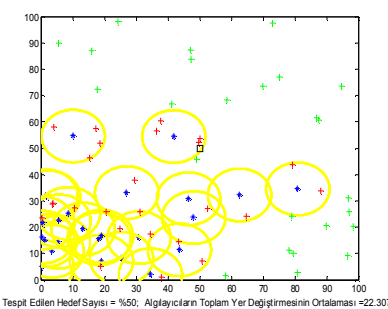

(e)

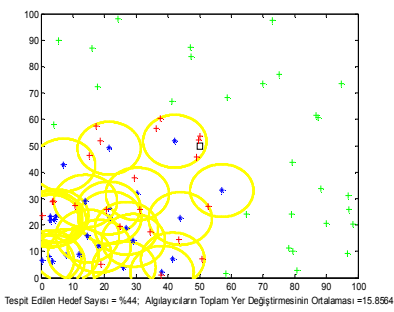

(g)

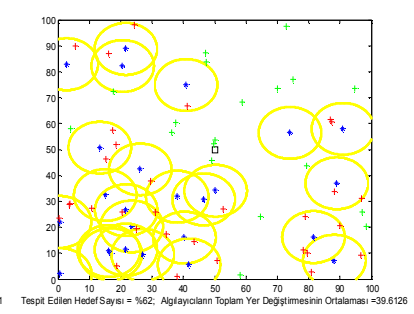

(b)

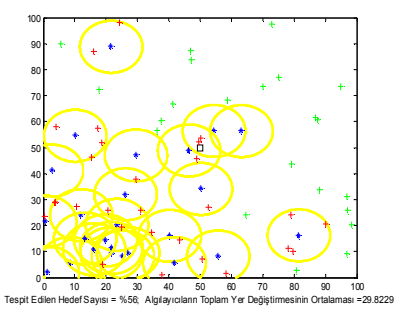

(d)

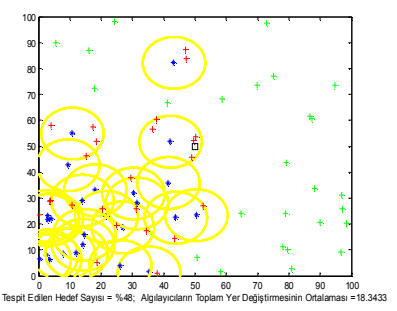

(f)
Şekil 8. NSGA-II ile 600. nesilden sonraki EP çözüm kümesi (a) EP çözüm kümesi \#1, (b) EP çözüm kümesi \#2, (c) EP çözüm kümesi \#3, (d) EP çözüm kümesi \#4, (e) EP çözüm kümesi \#5, (f) EP çözüm kümesi \#6, (g) EP çözüm kümesi \#7 (EP solution set with NSGA-II after 600 generations (a) EP solution set \#1, (b) EP solution set \#2, (c) EP solution set \#3, (d) EP solution set \#4, (e) EP solution set \#5, (f) EP solution set \#6, (g) EP solution set \#7)

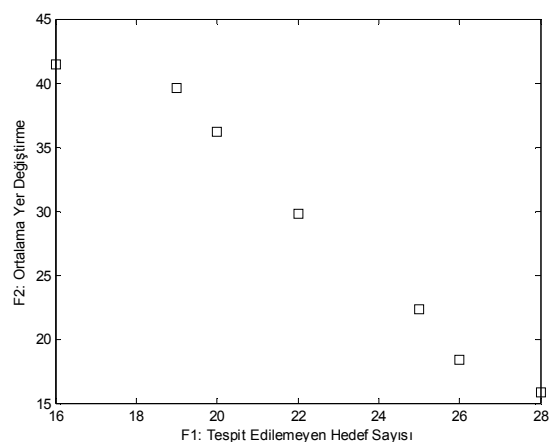

Şekil 9. NSGA-II ile EP domine-edilemeyen çözümlerin çizge olarak gösterimi (EP non-dominated solutions with NSGA-II as a graph) 
Tablo 1. MOEA/D ve NSGA-II ile niceliksel EP çözümleri (Quantitative results of EP solutions with NSGA-II and MOEA/D)

\begin{tabular}{|c|c|c|c|c|}
\hline & \multicolumn{2}{|c|}{ MOEA/D } & \multicolumn{2}{|c|}{ NSGA-II } \\
\hline & $\begin{array}{c}\text { (Kapsana } \\
\text { n Hedef } \\
\text { Sayısı \%) } \\
(\max )\end{array}$ & $\begin{array}{c}\text { (Ort. Yer } \\
\text { Değisisimi) } \\
\text { (min) }\end{array}$ & $\begin{array}{c}\text { (Kapsana } \\
\text { n Hedef } \\
\text { Sayisı \%) } \\
(\max )\end{array}$ & $\begin{array}{c}\text { (Ort. Yer } \\
\text { Değişimi) } \\
\text { (min) }\end{array}$ \\
\hline & $\begin{array}{c}\text { Uygunlu } \\
\text { k } 1\end{array}$ & Uygunluk 2 & $\begin{array}{c}\text { Uygunlu } \\
\text { k } 1\end{array}$ & Uygunluk 2 \\
\hline \multirow{11}{*}{$\mathrm{EP}$} & $\% 62$ & 41,6891 & $\% 68$ & 41,4601 \\
\hline & $\% 58$ & 39,993 & $\% 62$ & 39,6126 \\
\hline & $\% 54$ & 31,5947 & $\% 60$ & 36,2051 \\
\hline & $\% 50$ & 27,3574 & $\% 56$ & 29,8229 \\
\hline & $\% 46$ & 26,1052 & $\% 50$ & 22,3075 \\
\hline & $\% 42$ & 22,7671 & $\% 48$ & 18,3433 \\
\hline & $\% 40$ & 17,1958 & $\% 44$ & 15,8564 \\
\hline & $\% 38$ & 15,0043 & & \\
\hline & $\% 36$ & 9,8076 & & \\
\hline & $\% 34$ & 7,4836 & & \\
\hline & $\% 24$ & 6,2948 & & \\
\hline
\end{tabular}

Yukarıda yapılan benzetim çalışmalarına ek olarak algılayıcı ağların birbirinden uzaklaşmalarını sağlayan Ayırma fonksiyonu geliştirilmiştir. Ayırma fonksiyonu tüm algılayıcıların diğer algılayıcılar ile arasındaki mesafeyi hesaplayıp bu değeri maksimize etmeye çalışmaktadır.

Böylece algılayıcıların üst üste gelme ihtimali azalacağından MKAA ortamına dağılımı artacaktır ve kapsamayı arttıracaktır. Ayırma fonksiyonunun formulüzasyonu şu şekildedir:

Ayırma $=\frac{\sum_{i=1}^{n-1} \sum_{j=i+1}^{n} d\left(x_{i}, x_{j}\right)}{n}$

Uygunluk fonksiyonu sayısında bir değişikliğe gidilmeyip uygunluk fonksiyonlarından biri değiştirilmiştir. Buna göre yeni uygunluk fonksiyonları şu şekildedir: $f_{1}($ Uygunluk 1$)=$ Toplam kapsanmayan hedef sayıs1 $f_{2}($ Uygunluk $)=$ Toplam yer değiştirmelerin ortalaması / Ayırma değeri

Maksimizasyon fonksiyonu olan Ayırma fonksiyonunun maksimizasyonu bölen olarak yazıldığında Uygunluk2 değeri minimize edilmiş olmaktadır. Böylece tüm değerler minimizasyon işlemi yapmaktadır. Tablo 2'de Ayırma fonksiyonunun kısıtlara eklenmesinden sonraki oluşan 600 nesilden sonraki EP çözüm kümesi gösterilmektedir.

Performans değerlendirmesine ek olarak algoritmaların zaman karmaşıklık analizleri de dikkate alınmıştır. Zhang ve arkadaşları MOEA/D ve NSGA-II algoritmalarının analizini [16] nolu çalışmada detaylı olarak gerçekleştirmiştir. Buna göre MOEA/D $O(M N T)$ karmaşıklık değerine sahipken, NSGA-II $O\left(M N^{2}\right)$ gibi bir karmaşıklık değerine sahiptir. Popülasyon büyüklüğü olan $N$ değeri her zaman, komşuluk büyüklüğü $T$ ve amaç fonksiyonu $M$ değerinden büyük olduğu için MOEA/D algoritmasının NSGA-II'ye göre daha az karmaşıklığa sahip olduğu görülmektedir.

\section{SONUÇLAR (CONCLUSIONS)}

$\mathrm{Bu}$ makalede etkin kapsama kontrolü problemi adreslenmiştir. Bu problem dahilinde, kapsama ile yer değiștirme mesafesi arasında ödünleşim sağlayacak şekilde mobil düğümlerin konumlarını değiştiren çok amaçlı evrimsel algoritmalar incelenmiştir. Evrimsel algoritma tekniği olarak MOEA/D ve NSGA-II algoritmaları kullanılmıştır. Optimizasyon için kapsanan hedef sayısı ve yer değiştirilen ortalama uzaklık kriterleri dikkate alınmıştır. Uygunluk fonksiyonlarına karar verdikten sonra, ÇAEA teknikleri (MOEA/D ve NSGA-II) bir küme başlangıç çözümden bir dizi domine-edilemeyen çözüme evrimleşmektedir. Her bir domine-edilemeyen çözüm belirlenen amaç fonksiyonlarından birine yönelmektedir. İlk karşılaştırmalı sonuçlar

Tablo 2. MOEA/D ve NSGA-II'nin Ayırma fonksiyonundan sonraki çözüm kümesinin niceliksel gösterimi (Quantitative results with NSGA-II and MOEA/D after Seperate function)

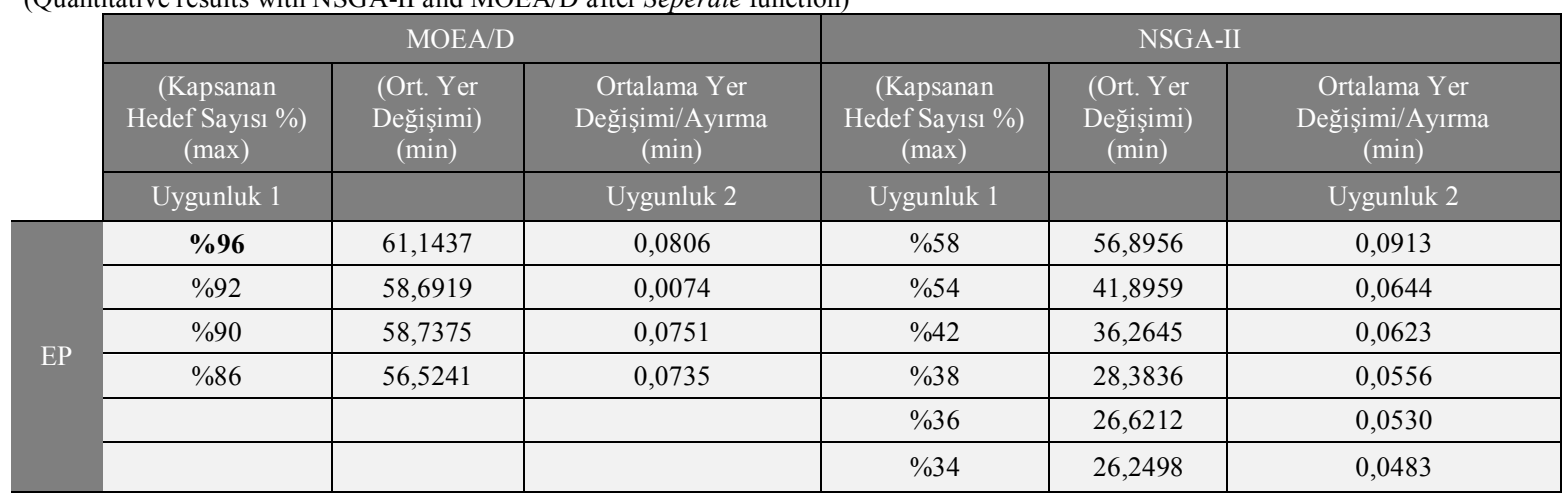


kıyaslandığında Uygunlukl dikkate alındığında NSGA-II algoritması MOEA/D algoritmasına göre kısmen daha iyi sonuçlar sunmaktadır.

İki algoritmanın da geçerli uygunluk fonksiyonları için kıyaslandığında birbirine yakın sonuçlar ürettiği görülmektedir. Kapsamanın çok iyi sonuçlar üretmemesi nedeniyle (\%60-\%70 oranında bir kapsama) Ayırma fonksiyonu ile uygunluk kriterlerinde iyileştirme yapılmıştır. Buna göre her iki algoritmanın da çözümleri Ayırma fonksiyonu eklenmeden önceki çözümlerle kıyaslandığında MOEA/D ile büyük bir gelişme sağlanırken, NSGA-II ile beklenen gelişme yakalanmamıștır. MOEA/D ile ortalama yer değiştirme ile az bir ödünleşim içerisinde kapsama oranının \%96'ya çıkarılması sağlanmıştır. Ayrıca, algoritmaların karmaşıklık analizi sonuçları MOEA/D algoritmasının NSGA-II'ye göre daha az karmaşıklığa sahip olduğunu göstermektedir. Kapsama oranın artması ile alan gözetleme, hedef tespiti ve takibi gibi çeşitli uygulamaların güvenilirlik ve performanslarının artması sağlanmaktadır. Ayrıca hareketli düğümlerin ortalama yer değiştirmelerinden kaynaklı enerji tüketimi kısıtlanarak ağın yaşam ömrü uzatılmaktadır. Örneğin, başlangıç durumunda belirli bir bölgeye rastgele bırakılan düğ̈̈mler ortamdaki hedefleri \%4'lük bir oranda (50 hedef için 2 hedefin tespiti) tespit etmektedir. $\mathrm{Bu}$ oran dügümmler ve hedefler ortama rastgele dağıtıldıkları için değişebilmektedir. Çok amaçlı evrimsel algoritmalar kullanıldığında ise bu hedef tespit oranının dramatik bir şekilde arttığı görülmüştür. Örneğin, MOEA/D ile $\% 96$ oranında (50 düğüm için 48 hedefin tespiti) hedef tespiti sağlanabilmektedir. Bu nedenle hareketli düğümlerin konumlarının belirlenmesi için MOEAD algoritmasının hem performans hem de kaynak kullanımı açısından daha uygun olduğu görülmüştür.

$\mathrm{Bu}$ çalışmalara ek olarak gelecekte yapılabilecek çalışmalara bakıldığında problem uzayı genişletilerek bağlantı ve güvenlik kriterleri incelenebilir. Birçok uygulama için MKAA'larda bağlantı ve güvenlik önemli kriterler olarak değerlendirilmektedir, bu nedenle bu kriterlerin ağ yaşam ömrü üzerindeki etkilerini görmek önemli bir araştırma konusudur. Ayrıca diğer çok amaçlı optimizasyon problemleriyle kıyaslamalar yapılarak daha geniş çaplı karşılaştırmalı sonuçlar üretilebilir.

\section{KAYNAKLAR (REFERENCES)}

1. Howard, A., Mataric, M. J. ve Sukhatme, G. S., "Mobile Sensor Network Deployment using Potential Fields: A Distributed, Scalable Solution to the Area Coverage Problem", In Proceedings of the 6th International Symposium on Distributed Autonomous Robotics Systems (DARS02), Fukuoka, 299-308, June 25-27 2002.

2. Zou, Y. ve Chakrabarty, K., "Sensor Deployment and Target Localization Based on Virtual
Fources", Proc. IEEE INFOCOM, Cilt 2, 12931302, 2003.

3. Wang, G., Cao, G. ve La Porta, T. F., "Movement-Assisted Sensor Deployment", IEEE INFOCOM, Cilt 4, 2469-2479, 2004.

4. Pac, M. R., Erkmen, A. M. ve Erkmen, İ., "Scalable Self-Deployment of Mobile Sensor Networks: A Fluid Dynamics Approach", Proceeding of 2006 IEEE/RSJ International Conference on intelligent Robots and Systems, 1446-1451, 2006.

5. Chang, R.-S. ve Wang, S.-H., "Self-Deployment by Density Control in Sensor Networks", IEEE Transactions on Vehicular Technology, Cilt 57, 1745-1755, 2008.

6. Cardei, M., Thai, M. T., Li, Y. ve Wu, W., "Energy-Efficient Target Coverage in Wireless Sensor Networks", IEEE INFOCOM'05, Cilt 3, 1976-1984, 2005.

7. Jia, J., Chen, J., Chang, G., Wen, Y. ve Song, J., "Multi-objective optimization for coverage control in wireless sensor network with adjustable sensing radius", Computers and Mathematics with Applications, Cilt 57, 17671775, 2009.

8. Konstantinidis, A., Yang, K., Zhang, Q. ve Zeinalipour-Yazti, D., "A multi-objective evolutionary algorithm for the deployment and power assignment problem in wireless sensor networks", Computer Networks, Cilt 54, 960976, 2010.

9. Konstantinidis, A., Yang, "Multi-objective Kconnected Deployment ve Power Assignment in WSNs using a problem-spesific constrained evolutionary algorithm based on decomposition," Computer Communications, Cilt 54, No 6, 960976, 2010.

10. Konstantinidis, A. ve Yang, K., "Multi-objective energy-efficient dense deployment in Wireless Sensor Networks using a hybrid problem-specific MOEA/D”, Applied Soft Computing, Cilt 11, 4117-4134, 2011.

11. Pradhan, P. M., Baghel, V. ve Bernard, M., "Energy Efficient Layout for a Wireless Sensor Network using Multi-Objective Particle Swarm Optimization", 2009 IEEE International Advance Computing Conference, Patiala, India, 65-70, 2009.

12. Jourdan, D. B. ve Week, O. L., "Layout Optimization for a Wireless Sensor Network Using a Multi-Objective Genetic Algorithm", Vehicular Technology Conference, Cilt 5, 2466-2470, 2004.

13. Deb, K., Multi-Objective Optimization Using Evolutionary Algorithms, Wiley and Sons, 1st Edition, 25-40, 2001.

14. Coello, C.A.C., Lamont, G.B. ve Van Veldhuizen, D.A., Evolutionary Algorithms for Solving Multi-Objective Problems, Springer, 2nd Edition, 116-120, 2007. 
15. Knowles, J. D. ve Corne, D.W., “Approximating the nondominated front using the Pareto archived evolution strategy", Evolutionary Computation, Cilt 8, No 2, 149-172, 2000.

16. Zhang, Q. ve Li, H., "MOEA/D: a multiobjective evolutionary algorithm based on decomposition", IEEE Transactions on Evolutionary Computation, Cilt 11, 712-731, 2007.

17. Li, H. ve Zhang, Q., " Multiobjective Optimization Problems With Complicated Pareto Sets, MOEA/D and NSGA-II", IEEE Transactions on Evolutionary Computation, Cilt 13, No 2, 284-302, 2009.

18. Zhang, Q., Liu, W., Tsang, E. ve Virginas, B., "Expensive Multiobjective Optimization by MOEA/D with Gaussian Process Model”, IEEE
Transactions on Evolutionary Computation, Cilt 14, No 3, 456-474, 2010.

19. Srinivas, N. ve Deb, K., "Multiobjective optimization using nondominated sorting in genetic algorithms", Journal of Evolutionary Computation, Cilt 2, No 3, 221-248, 1994.

20. Deb, K., Pratap, A., Agarwal, S. ve Meyarivan, T., "A fast and elitist multiobjective genetic algorithm: NSGA-II", IEEE Transaction on Evolutionary Computation, Cilt 6, No 2, 182197, 2002.

21. Özdemir, S., "Secure Data Aggregation in Wireless Sensor Networks via Homomorphic Encription," Journal of the Faculty of Engineering and Architecture of Gazi University, Cilt 23, No 2, 365-373, 2008. 
